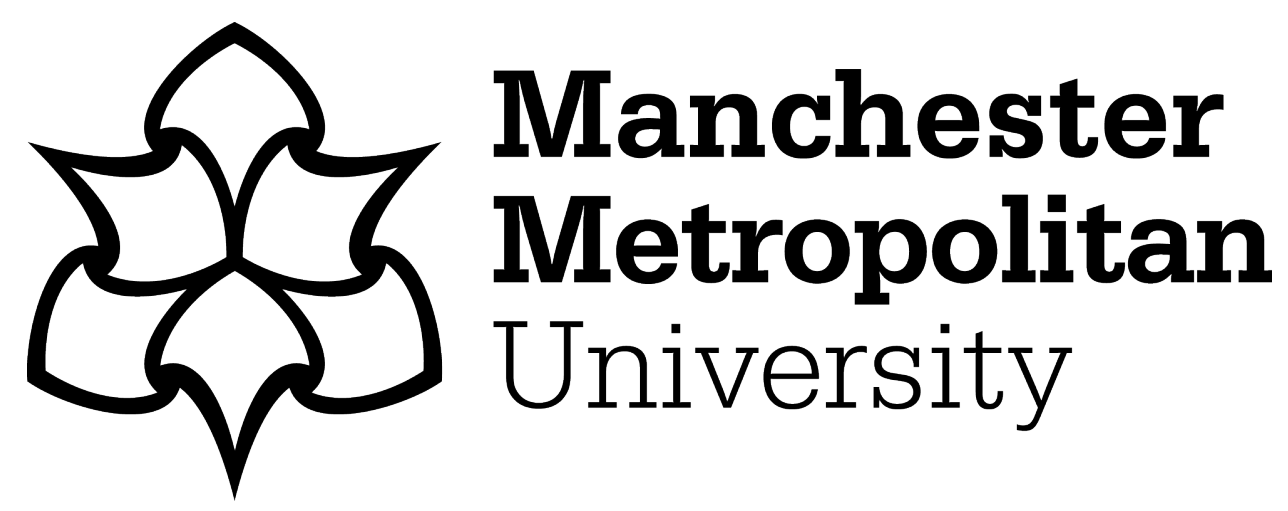

Gusmão Caiado, RG, Leal Filho, W, Quelhas, OLG, Luiz de Mattos Nascimento, D and Ávila, LV (2018) A literature-based review on potentials and constraints in the implementation of the sustainable development goals. Journal of Cleaner Production, 198. pp. 1276-1288. ISSN 0959-6526

Downloaded from: https://e-space.mmu.ac.uk/621843/

Version: Accepted Version

Publisher: Elsevier

DOI: https://doi.org/10.1016/j.jclepro.2018.07.102

Usage rights: Creative Commons: Attribution-Noncommercial-No Derivative Works 4.0

Please cite the published version 


\title{
A Literature-Based Review on Potentials and Constraints in the Implementation of the Sustainable Development Goals
}

Gusmão Caiado RG, Leal Filho W, Quelhas OLG, Luiz de Mattos Nascimento D, Ávila LV

\section{Journal of Cleaner Production 198:1276-1288 10 Oct 2018}

\begin{abstract}
The Sustainable Development Goals (SDGs) agreed by Heads of Government in 2015 represent a major multilateral effort to shift the world towards more sustainable and resilient pathways, also taking into account the needs of developing countries. The SDG Agenda calls for a global partnership - at all levels - between all countries and stakeholders who need to work together to achieve the goals and targets, including a broad spectrum of actors such as multinational businesses, local governments, regional and international bodies, and civil society organizations. The purpose of this paper is to present a comprehensive review of the literature and develop a novel framework in order to tackle the barriers and challenges to operationalize and monitor the implementation of the SDGs. To achieve this, this paper reports on a state-of-the-art review of the SDGs, with a particular emphasis on their applications and linkages with sustainability science and aspects of knowledge management. This paper also reviews the rationale and aims of the Sustainable Development Goals, outlines some of the problems and barriers related to their implementation, and presents some areas which deserve future attention. Ultimately, this paper seeks to uncover the various gaps and suggests some means via which some of challenges seen in the accomplishment of the 17 SDGs may be faced.
\end{abstract}

Keywords: Sustainable Development Goals; Sustainability Science; Knowledge Management; Interdisciplinary; 2030 Agenda; Stakeholder Engagement.

\section{Introducing the Sustainable Development Goals (SDGs)}

The concept of Sustainable Development (SD) was historically coined by the United Nations Commission on Environment and Development's (Brundtland Commission) report, in a document entitled Our Common Future. This concept advocates that development must be planned in order to "meet the necessities of the present generation without harming the future generation's capacity to meet their own" (Brundtland et al. 1987). However, according to Govindan et al. (2013), one of the main 
challenges for sustainability is to operationalize the resolutions of the Brundtland Commission in order to guide organizational decisions.

The current concepts of SD are increasingly more important than they were two decades ago, due to it spanning beyond strictly environmental, economic and social development concerns, towards impacting people's very survival (Kumi et al. 2014). In this context, there is a need for science to serve politics, as well as dealing with the government's and multiple shareholders' requests when they are met with the challenge of attaining sustainable development (Aricò 2014).

In the Rio+20 United Nations Summit of 2012, the idea of creating the SDGs emerged, in which members of states agreed to adopt a set of guidelines towards global development in order to increase the baseline for developing countries and poorer populations (Gupta and Vegelin 2016), as well as to build a stronger commitment towards people-centered development, human rights, and environmental sustainability (Javasooria 2016).

The SDGs were set out through a series of measurable targets, and demanded at several levels - a great amount of worldwide cooperation and effort when it came to monitoring, which unfortunately is rarely even possible (Giupponi and Gain 2016). The Rio+20 Conference, in its final document, The Future We Want, approved a process while disregarding several others, so as to negotiate a consensus on the SDGs (UN General Assembly 2012). Therefore, the result of Rio+20 was designed to be qualitatively different from the Millennium Development Goals (MDGs) in many ways, and the SDGs aimed to be more inclusive to a number of stakeholders in several levels of governance (Gellers 2016).

Following The Future We Want, the UN's document Transforming our World: The 2030 Agenda for Sustainable Development includes a declaration of the 17 SDGs 
and 169 other goals, along with monitoring and review measures (Gupta and Vegelin 2016). The SDGs were formulated through an extensive participatory process and went through high-level panels such as Open Working Groups (OWG) along with numerous inquiries, until a negotiated document was finally approved by the heads of state. The heads of state established five fields of critical importance, or the "five Ps" of the 2030 SDG Agenda, which are people, planet, prosperity, peace and partnerships (Jayasooria 2016).

As Aitsi-Selmi et al. (2016) state, the SDGs - successors to the MDGs - were agreed upon on September 2015 in New York, USA, by 193 countries, and focused on an extremely comprehensive set of development goals. When it comes to losses and disasters, the SDGs emphasized sensibilities to vulnerabilities created by gender, age and disabilities.

It is expected that the new Sustainable Development Goals and their targets - in force since January 1st 2016 - will guide the decisions to be made throughout the next fifteen years and will fundamentally influence international politics and the finance available for sustainable development, and so will therefore shape the future political efforts and the dynamics of natural capital (Terama et al. 2015). Moreover, governments are expected to use these goals to fight extreme poverty and to face the challenges that come with ensuring environmental, social, and economical sustainable development in their respective communities (Choi et al. 2016).

However, much like the MDGs, the SDGs do not contain a specific and clear goal relating to the growth of the world population and the new goals for 2030, in an ecological context (Bergaglio 2016). Subsequently, there is the potential for the SDGs to mobilize academic communities, as well as professional practice communities and social movements around them, in order to demand relational change and liability for 
those who execute the objectives. They may therefore be reinforced by the commitment to the inclusive development principals towards all involved stakeholders (Gupta and Vegelin 2016). For this to happen, each nation, state or country has the primary responsibility of mobilizing and raising financial resources, which will in turn promote new partnerships between the private sector and civil society (Jayasooria 2016).

According to Stafford-Smith et al. (2016), the goals of the SDGs defined an agenda for the sustainable development of all nations which adhered to economic growth, social inclusion and environmental protection. In this context, the intention of this paper is to develop a novel framework to guide researchers, practitioners, community leaders and entrepreneurs, in order to teach them how to tackle the barriers and challenges that come with operationalizing and monitoring the implementation of the new 2030 agenda. To achieve this, we have conducted a state-of-the-art review of the emerging SDGs with particular emphasis on their application and linkage with sustainability science and aspects of knowledge management. We have identified trends and lessons to be learned in order to aid future decision makers in their applications and to bridge the gap between scientific knowledge and the decision-making processes of governments. This paper seeks to uncover gaps and inconsistencies in the literature and explore new critical research paths to sustainable development. To do this, this paper aims to systematically collect and critically analyse the existing in-depth discussions and contributions on SDGs in order to provide a better comprehension of the interconnections between objectives. Considering this, the main research questions addressed in this review are:

- What are the emerging issues in the research on SDGs?

- What are the main paths and recommendations suggested to overcome the problems and obstacles facing SDGs implementation? 
- What are the challenges to the promotion of an operational solution in order to measure or monitor the implementation of SDGs, supporting the evaluation of sustainability?

This study contributes to the Sustainability Science literature on two grounds. Firstly, as suggested by several authors, (Beynaghi et al. 2016; Hutton and Chase 2016; Mugagga and Nabaasa 2016) by applying an extensive literature review. Secondly, this paper makes a contribution by proposing a continuous cycle for the achievement of the Sustainable Development Goals, which holistically engages and involves all stakeholders in a collaborative problem solving and iterative process. This includes an interdisciplinary approach, towards the mobilization of global operational knowledge through higher education, information technology applications and mutual trust for the promotion of prosperity of all at a long term sustainable and more inclusive world.

This article is organized as follows. Section 2 covers the research methodology followed within this paper. Section 3 presents a literature review about some operational issues of SDG implementation, sustainability science and some problems and obstacles facing the implementation of the SDGs. Section 4 proposes a novel framework and describes some guidelines to achieve the SDGs and improve the understanding and knowledge management of sustainability science. Section 5 presents the lessons that have been learned from the implementation of SDGs. Section 6 concludes and presents suggestions for future research.

\section{Research methodology}

A literature review was adopted as a research methodology in order to locate existing relevant peer-reviewed studies based on prior formulated research questions and to evaluate their respective contributions. The target Electronic Databases (EDs) 
were Elsevier (sciencedirect.com), Scopus (scopus.com) and Springer (springerlink.com). The research has a number of classifications for the nature of the goals, including: exploratory and descriptive, inductive logic, with data collection from primary and secondary sources, and qualitative approaches. Regarding the results found, the methodology represents applied research, using the literature to map emerging issues related to the SDGs.

We searched databases from 2009 to November 15, 2016, in all fields using the terms: (“SDGs" OR “Sustainable Development Goals” OR “post-2015 agenda” OR “2030 agenda") AND (“sustainability science" OR “education” OR "knowledge”). This review consisted of four steps: (1) formulating questions for the research; (2) selection and evaluation of studies; (3) analysis of the content of selected articles; and, (4) the description of the results. The search steps and selection results are presented in Figure 1. The first step was to find what the problems, barriers, challenges and obstacles for the implementation of SDGs were in the world and to find out how it is possible to monitor or measure their operationalization. In the second stage, we used the search terms in the determined period of time. We considered only scientific papers from journals and reviews that were related to the Environmental and Social Sciences, Engineering and Management areas that were also available in the English and Spanish languages. In the third stage, for all titles that related broadly to the topic of Sustainable Development Goals (e.g., titles mentioning SDGs), all authors reviewed the abstracts and read the complete article of all relevant texts as well as for those for which no abstract was available. We also searched the Sustainability Science Journal database and reviewed reference lists from relevant articles. Further, we talked with university professors and other experts to identify additional studies. After analyzing the articles, only those containing explicit references to the SDGs were used. Appendix A presents a list of the 
55 selected articles in our bibliographic portfolio with the number of citations for each.

A novel framework was built based on state of the art recommendations from the scientific literature. 


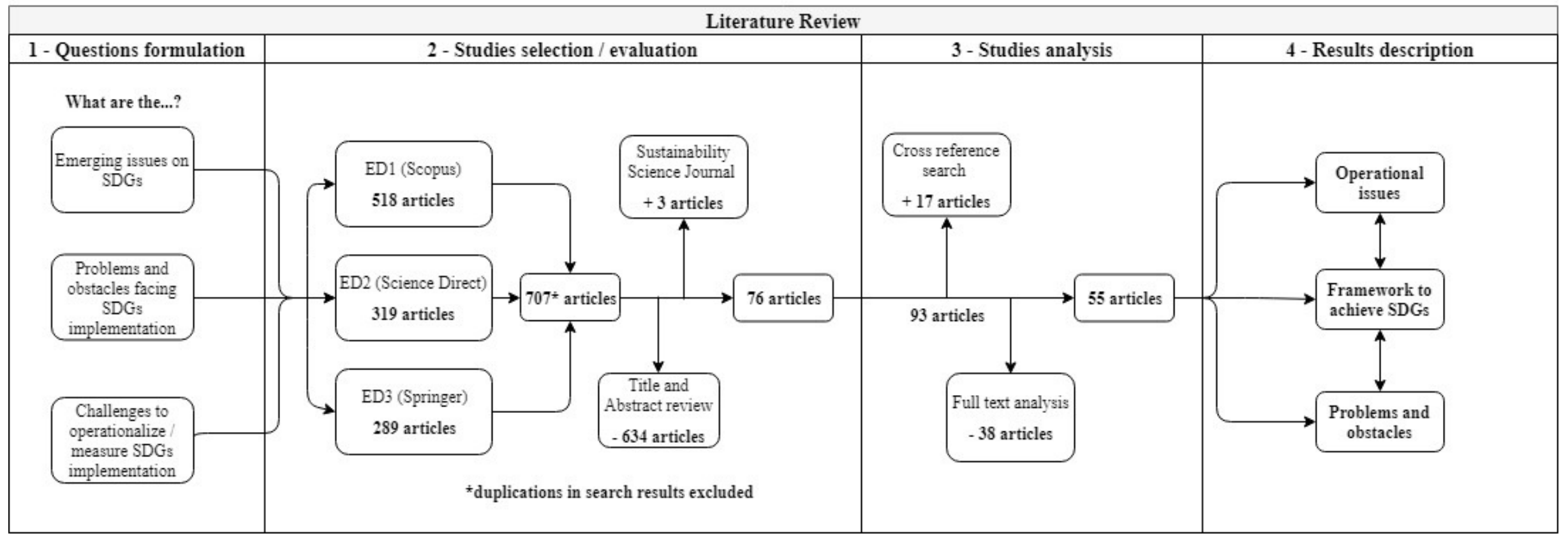

Fig. 1 Literature review steps with selection process of the bibliographic portfolio 
As Hák et al (2016) suggest, when it comes to a conceptual framework, all of the goals and indicators must be carefully analyzed by specialists and scientists in order to develop and/or apply the proper approaches. Therefore, in seeking to validate the proposed framework, a presentation event with interviews was conducted by a moderator (Daniel Nascimento) and a focus group. The selected experts contained at least 10 years of experience in sustainable management in addition to a master's degree in science. The event took place on January 27, 2017 at the Pontifical Catholic University of Rio de Janeiro, Brazil. The implementation of focus groups is one of the most used methods for qualitative research. The goal is to bring together small groups of 4 to 12 people to discuss a topic of mutual interest raised by a moderator.

In this context, in order to be effective in this method, the steps followed to carry out Focused Groups (Ribeiro 2003, Tortorella et al. 2008) were: (1) Planning, which considers the objective of the event, as well as an informational structure in search of systematic knowledge, details of the necessary inputs and clear rules (participants, place, questions and moderator); (2) Conducting the interviews, in which the data were stored by annotations made by the moderator while conducting meetings of the most important points; and (3) Data analysis through a transcription of records and a further analysis of responses collected in the form of reports composed of summaries of the discussions that served to complete the diagnosis and identify actions to be taken to improve the framework. The outcomes from these focus group interviews are presented in subsection 4.1. Then, based on the triangulation between the theory, the results of the applied study and the direct observation of the authors, a list of guidelines to achieve the SDGs and to tackle sustainability challenges was proposed. 


\section{Literature review}

\subsection{Implementing the SDGs: some operational issues}

The SDGs represented a top-down approach designed by the political elite based on the objectives created during the United Nations' summits and by conferences in the 90's (Brolan et al. 2014). However, according to Sachs (2012), the path to SD should not follow a top-down approach, and should rather follow a highly-powered problem resolution network which involves universities, companies, NGOs, governments, and most importantly - the young people of the world. Young people are those who will become the specialists and leaders of a new and deeply challenging age.

Kumi et al. (2014) outlined at least three important matters which should guide operational policies which follow the SDGs: a change of the conventional approach when it comes to poor people from pro-growth to pro-poverty growth; the necessity of taking equity seriously, and lastly, the necessity of tackling power relations and giving poorer people a voice.

According to the suggestions of Jayasooria (2016), the global SDG agenda provides Social Workers an opportunity to redefine their relative role to become people of empowerment, social-economic development, human rights and the environment. It also creates a positive and holistic intervention framework for practice, allowing Social Workers to utilize this approach based on a worldwide commitment during the entirety of the 2030 agenda.

The SDGs will provide a wider framework to tackle the concerns of the Bottom 40 group of the socioeconomic gap (B40), ensuring not only equality of access, but also equal results (Jayasooria 2016). In summary, the objectives of raising the baseline must be complemented by a reduction at the top of the socioeconomic spectrum (Gupta and Vegelin 2016). 
According to Stafford-Smith et al. (2016), more attention must be given to the interconnections between the objectives in three main areas: sectors, agents and countries. Similarly, more consideration ought to be given to time intervals, in order to obtain a systematic overview and an integrated approach for the implementation of the SDGs, ultimately striving for an integrated agenda. Based on science's global perspective and on the practice of sustainability presented by Future Earth, in order to improve these connections, they must encompass seven UN categories of implementation means in 17 SDGs: finances; technology; qualification; political integrity; partnerships; and finally; data, monitoring and accountability.

Furthermore, Stafford-Smith et al. (2016) suggest seven recommendations that countries must ensure a commitment to:

- Legislative and regulatory incentives to the "patient capital" - investment and capital which measures payback throughout decades - particularly in lowincome countries;

- A partnership approach among countries with lower revenue and resources availability with those with larger ones, in order to co-produce knowledge, technology and processes for sustainability;

- A commitment to incorporate systematic thought through all levels of education;

- Integrated SD plans which reinforce ties between fragmented sectors and promote political integrity;

- Political leadership on SD, for example in the higher branches of government, such as the President/Prime Minister level as well as high up in the hierarchy of the Executive Branch;

- Indicators for integrated SDGs, supported by "essential SD variables" as a common report standard which stimulates or demands that agents work together. 
To Stevens and Kanie (2016), the SDGs represent a different approach, and, in order to unfold the global governance practices which may contribute towards a transformation towards sustainability, it is essential to analyze the decision-making processes and the transformative ideas which are captured in these decisions. Therefore, the potential of the SDGs to transform the dominant governance approaches to sustainability remains a significant matter to be addressed (Stevens and Kanie 2016).

Moreover, the assessment of the SDGs is an essential task for the UN and for its member States, and the production and use of quality data is being increasingly recognized as an essential task for the assessment, monitoring and tracking of SDGs. (Choi et al. 2016).

The biggest challenge today is to guarantee an economic development which allows the underprivileged to escape poverty without dooming future generations to an environment which is even more degraded than the current one (Mboumboue and Njomo 2016).

\subsection{Sustainability Science as a way to achieve SDGs}

The social, cultural, economic and environmental challenges faced by humanity are becoming more urgent, complex and interrelated, and are ultimately increasing the connection between science and society (Aricò 2014).

According to Dockery et al. (2015), sustainability is an iterative process, which includes multiple perspectives and disciplines. Wuelser and Pohl (2016) state that the investigation of SD requires researchers to align the production of scientific knowledge with concrete social problems, and in this process, it seems to be crucial to conceive of contributions from relevant political knowledge for sustainable development. 
To Aitsi-Selmi et al. (2016), the implementation of the Hyogo Framework is a lesson for the necessity to bridge the gap between scientific knowledge and the governments' decision-making processes. Governmental decision-making aids in the absorption and use of scientific knowledge, including the creation of technological innovations.

Scientific considerations are of the utmost importance because research is considered to be a scientific effort. It is clear that the inclusion of non-academic agents and stakeholders exponentially increases the relevance of research (Wuelser and Pohl 2016).

However, according to Terama et al. (2015), in an age of growing populations, global consumption and increasingly critical environmental consequences to inaction, it is a global challenge to translate the body of knowledge resulting from the SDGs into political action. A recent paper (Leal Filho et al. 2015) has weighed in on the implications of these objectives to higher education, in the post-United Nations decade on Education for the process of transformation to sustainable development.

In a case study in Malawi, Holm et al. (2016) suggested that in order to communicate the science of water quality and its health risks to developing countries, it is necessary to ensure that samples are analyzed and collected by experienced professionals. The purpose is to compile reference data and to deliver an efficient risk presentation back to the families, in order to motivate behavioral change and effectively protect future hydrological resources in addition to human health.

Moreover, according to Munamati et al. (2016), in order to contribute substantially to the achievement of the SDGs, an investment in education must be explicitly considered, given the developed competencies, technical expertise and skills that are required for the development and implementation of policy. It is also important 
to emphasize research and technology which promotes low-cost and innovative sanitary development. In turn, this supports and ensures the recovery and safe reuse of residual water products.

By analyzing all different projects and studying a set of diverse matters of sustainability challenges, Wuelser and Pohl (2016) acknowledged three types of scientific contributions to SD: researchers provide a better and fundamental comprehension of certain phenomena, while outlining patterns for the sustainable use of resources and outlining set parameters selected for specific contexts.

According to Aricò (2014), the science of sustainability is an emerging field which promotes an interdisciplinary approach. Sustainability depends of various fields of application and relates closely to ethical arguments on current responsibilities to future generations. He also states that Education for Sustainable Development (ESD) emphasizes the integration of key-matters of sustainable development through teaching and learning participative methods, in order to empower students to adopt measures for sustainable development and to identify points of complementation between ESD and the science of sustainability in the following manners:

- The science of sustainability supports the content which is taught in ESD, contributing to the concept of a "sustainable alphabetization" while ESD promotes such alphabetization;

- The science of sustainability, as well as ESD, empowers people to overcome the sharing of knowledge through interdisciplinary multi-stakeholder approaches. This allows them to evaluate the symptoms of unsustainable development properly, as well as the root causes for "unsustainability" which is essential in the current model; 
- The science of sustainability provides the necessary scientific support for the transition to sustainability while ESD approaches the public and reorganizes the educational system towards sustainability.

Furthermore, according to Sachs (2012), while the SDGs require an unprecedented mobilization of global operational knowledge in various sectors and regions, social media and information technology provide an incomparable opportunity to solve global problems concerning the main challenges of SD. This is due to the fact that more and more individuals are resorting to online networks of collaboration, crowdsourcing, group-resolution of problems and open-source solutions facilitated by software and applications.

\subsection{Problems and obstacles to implementing the "Sustainable Development Goals"}

There are current obstacles when it comes to the way in which the science is conceived and relates to education that hinder interdisciplinarity. The emerging field in the science of sustainability tries to, among other things, clarify how "a new generation of science" could be conceived in order to promote more integrated ways of thinking to tackle complex matters in society (Aricò 2014).

According to Kumi et al. (2014), the principles of a neoliberal economic agenda such as mercantilization, deregulation, privatization and various cuts in public spending, may somewhat hamper sustainable development by increasing poverty and inequality. Kumi et al. (2014) also suggest that the economic theories of neoliberalism would have implications for the SDGs, and would come to be part of a cardinal agenda that would guide social, economic and development intervention in the coming fifteen years. 
Further, provisions for the implementations of the SDGs in the UN MemberStates were not elaborated in detail during the negotiation stage of the principles of national sovereignty and subsidiarity. As a result of Agenda 2030 being so broad and extensive, it is harder to define implementation and eventual responsibility processes (Person et al. 2016).

Moreover, a landscape approach theory - an integrated and multifold strategy which aims to bring together several actors and sectors which transcend the traditional management limits - remains incomplete, and the obstacles to its implementation persist (Reed et al. 2016).

According to Koehler (2016), with regards to gender inequality policies amongst other types of inequality, the SDGs are modest, and display no consistency. This is mainly due to the fact that political proposals concerning gender and climate justice are often sparse, gradual and fragmented.

As Van Vuuren et al (2014) state, there seems to be a huge gap between the conception of a long-term goal and the current short-term policies implemented by political representatives.

Challenging scenarios force political decision-makers to employ different combinations of technological and consumption change measures in order to achieve the desired set of goals for sustainability. It is important for them to show that marginal improvement will not be sufficient to achieve a set of goals in sustainable development, because in order to achieve these goals, transformative change is required (Van Vuuren et al. 2014).

Through the analysis of risks and obstacles when it comes to the development of renewable energy in Camarões, Mboumboue and Njomo (2016) have identified that corruption and bureaucratic red tape were the main obstacles to the implementation of 
renewable energy, hampering SD as well as environmental protection. Despite this, Mboumboue and Njomo suggest that resources must be explored at an optimal level, so as to improve life quality for all and have a positive impact on society in general.

Cooperation between sectors, so necessary to achieve synergy in well-being goals, is a distinct challenge. The potential combination of private interests, mechanisms for blaming weaker links, and the lack of transparency mean that these objectives may be implemented without balancing the needs of the natural environment with other well-being objectives (Waage et al. 2015). As far as resources are concerned, the UN system has made provisions for substantial financial support by means of the Sustainable Development Goals' Fund. This has been set-up with the aim of supporting projects, but many organisations encounter problems, especially the lack of specific details on how to submit project ideas and access support.

Jasovsky et al. (2016) analyze how specific SDGs are impacted by antimicrobial resistance - a flaw in which the system demands an answer between sectors - and they emphasize the need for greater international collaboration and an improved distribution of responsibilities. Moreover, Jasovsky et al. (2016) suggest several steps for a wider involvement of countries and agencies in the $\mathrm{UN}$ in order to promote actions between global sectors concerning antimicrobial resistance and the need for an adaptable and multifold approach which acts on all SDGs and involves multiple stakeholders.

To Frey et al. (2016), while the objectives are not framed in terms of international human rights standards, its indicators should be selected from a group of technical experts, working behind closed doors. In order to advance these indicators, the following should be working together: Governments, international organizations, civil society and financial backers who were part of the global consultation. 
According to Shan and Khan (2016), the evaluation of sustainability results is not so easy to measure due to the complex inter-relation between the indicators, the lack of consensus about the definition of sustainability in the existing literature, and the choice of indicators which are subject to requirements and the opinions of the participants.

According to Flores Baquero et al. (2015), an approach based on aggregate results central tendency estimators does not provide any special incentive to focus and reach marginalized groups. From this, in the age of the SDGs, an assessment of the access to water at a global level determines a single indicator "for all cases", which is excessively simplistic in some contexts and does not demonstrate the existing inequalities.

For Giupponi and Gain (2016), evaluations based on indicators are a pragmatic operational solution to support the monitoring of phenomena through a series of static imagery on the state of the variables of the social and environmental system. Following that, it is important to later communicate its evolutions in a concise an efficient manner. However, the main challenge of monitoring the implementation of SDGs will be the availability of comparable gross global data in detail and proper quality in regular time intervals.

In research conducted by Malik et al. (2015), the authors highlight the fact that, globally, the main reasons for the challenges faced in the construction of comparable performance measures are: a lack of consistent definitions, report protocols and a central data repository for residual water treatment.

According to Urmee and Md (2016), the backbone of a sustainable long term program is an understanding of the attitudes and energetic needs of the community and an involvement of that community in the planning and conception of such programs. 
Different communities have different social and cultural attitudes which could potentially harm the successful implementation of electrification programs in rural areas.

The hidden differences between various points of view concerning the city and urban processes tend to become more explicit in the following decade due to the enormous diversity of necessities and experiences in the cities, as well as due to divergent intellectual understandings of the urban debate and its relationship to sustainable development (Barnett and Parnell 2016).

\section{A novel framework and guidelines to achieve the SDGs and improve the understanding and knowledge management of Sustainability Science}

Based on the separate contributions of SDGs in the literature review, it was possible to develop an integrated innovative framework which will help governments, researchers and organizations to better understand how to achieve the SDGs by using scientific knowledge management in order to recognize and tackle concrete societal problems.

Several authors have proposed frameworks for sustainable management with a focus on local organizations, referring that is, to meeting one or more goals for sustainable development (Labuschagne et al. 2005, Aragon-Correa et al. 2015, Maas et al. 2016). In this context, it is noted that scientific contributions are exploited in isolation (Deloitte and CSR Netherlands, 2015). Figure 2 presents a management model for implementing the 17 SDGs defined by the United Nations. The differential of this model is the proposition of a cycle for the implementation, monitoring and continuous improvement of the 17 goals in a global way, proposing a model of collaborative management to interconnect concepts and stimulate the adherence of the guidelines by 
the nations. In this model, a set of actions in favor of innovations for sustainable development are advocated. In the first step of the cycle, education and information, research is carried out in the various areas of knowledge with a focus on joining skills around the world and proposing methodologies or technologies. The second step is to transform research and development into new sustainable products, processes or services. From there, in step three, innovation is implemented, with an emphasis on respecting the constraints of each region. Finally, the continuous monitoring of goals, targets and good practices is carried out.

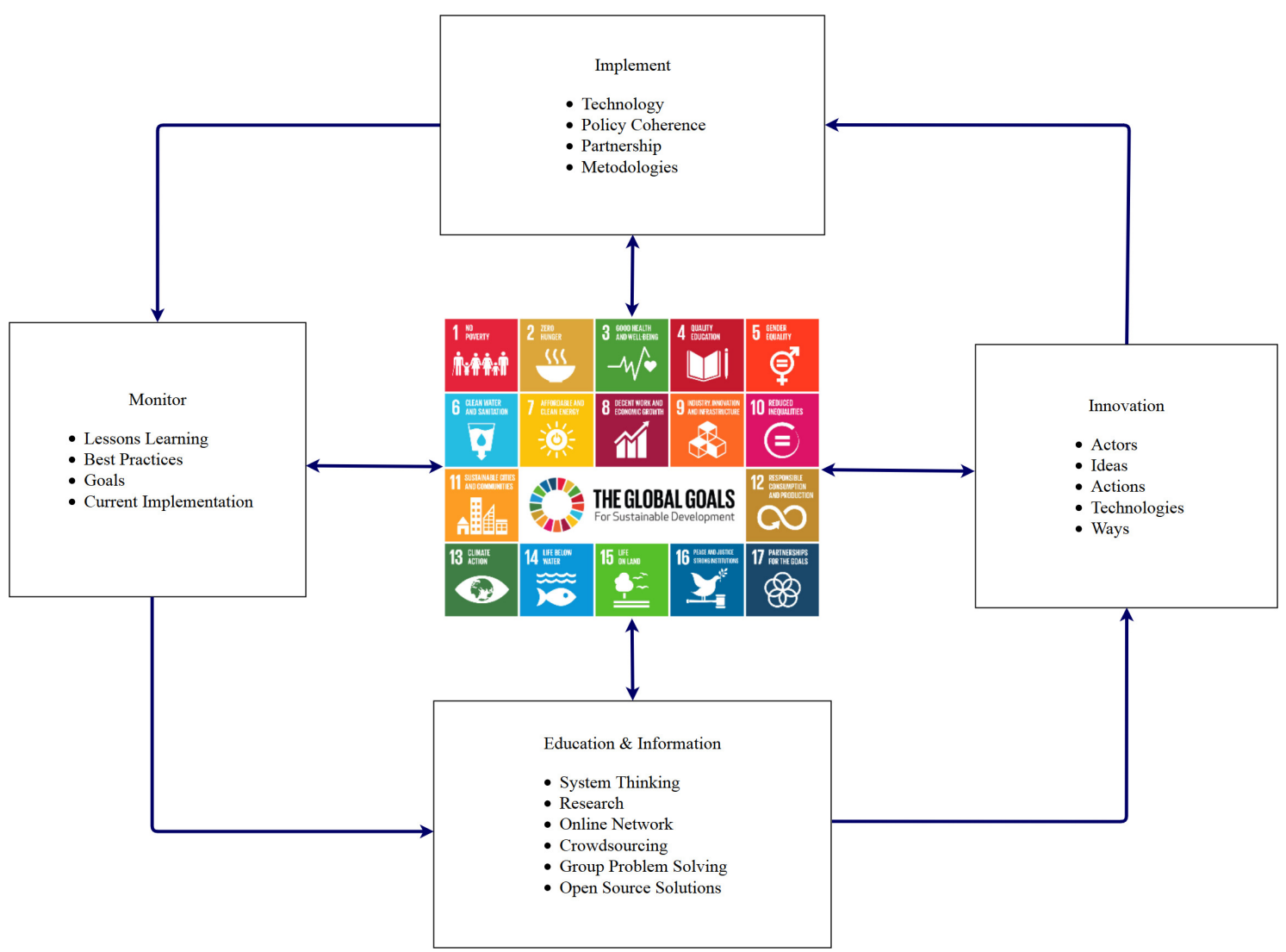

Fig. 2 Innovative framework to improve SD knowledge management to achieve SDGs

Therefore, Figure 2 offers a continuous cycle for the achievement of the Sustainable Development Goals. First of all there should be a collaborative problem solving network that connects as many stakeholders as possible, as well as all sectors and countries with multiple levels of governance. It is important to note that there 
should be an integration between the 5P's throughout this process. Following the interconnection between problems and investment in education and information technology, there should be participatory teaching and learning that involves software and applications with experts from different disciplines in order to develop inter/transdisciplinary projects and programs designed to solve complex problems of sustainability science. This step depends on systematic thinking at all levels of education and political leadership on SD, including, for example, G20 cooperation. From this step, new ideas, actions, technologies, or even actors are provided, making it possible to generate innovative products or services that implement or monitor the SDGs. The 'Implementation' step encompasses seven categories designed to implement the goals, and the 'Monitoring' step depends on the quality of data, multiple scales and integrated indicators that are supported by essential SD variables.

Moreover, it is worth emphasizing that there must be legislative and regulatory incentives. There must also be significant partnership working between lower and higher income countries designed to produce knowledge and engagement from leaders and experts from universities, businesses, non-governmental organizations, governments and young people in order to effectively tackle sustainability challenges. In this way, the implementation and monitoring of the SDGs will generate more cooperation in a more open and transparent playing field, all while fostering a sense of trust, promoting equal access and outcomes, respecting human rights and recovering global sustainability.

\subsection{Focus Group Interviews outcomes}

The validation of this framework was carried out in an event to present and discuss the sustainable management model, guided by the goals of the United Nations. 
Concerning the educational and informational stage, focus group experts emphasized that educators have to teach their students to think, to discover, to develop their skills and abilities and must break the paradigms of the traditional school, ceasing to be just an information transmitter. Thus, in this new era, information and communications technology (ICT) are seen as instruments for the construction of knowledge. It was expressed in this comment by one of the interviewed: "whoever is in school today will learn by doing, through different experiences and projects, knowledge of concepts from the fourth industrial revolution such as computer language and artificial intelligence are a watershed to achieve a competitive differential. In my view, we have reached the education 4.0 era and innovative teaching solutions are making a big difference". In line with the findings of Chin and Jacobsson (2015), the interviews also revealed that education via ICT enable new ways of learning, which is decisive in connecting global development goals to local realities.

Concerning the innovation stage, the filtering process of innovation in order to transform products, processes, services and materials into sustainable business is a point of focus so that prototypes are more likely to meet the real needs of society in a continuous and incremental way. In this context, we discussed the mandatory selection and prioritization of these innovations to be implemented at appropriate times.

With respect to the implementation stage, there is a need to: promotion of campaigns against social, race and gender inequality; more technological, educational and financial partnerships and exchanges between high-income and low-income countries; creation of drug, food and water collection centres for donation to the poorest populations; mobilization of companies and philanthropic institutions to meet global development goals; and integration of environmental concerns into national and sector strategic planning through a top-down approach. Hence, the industry experts 
emphasized that a collaborative and digitized education and the realization of more applied researches would already be a good starting point when attempting to seek innovations for sustainable development and thus implement SDGs.

With respect to the monitoring stage, it was agreed that the metrics aligned with the goals defined by the United Nations and that the collection of standardized data, feeding key performance indicators are fundamental for the monitoring and control of the global evolution of sustainable development. Therefore, from the proposed framework, one should create metrics for each stage and propose minimum amounts of information so that each country can contribute with its respective data. Finally, there is a need for continuous monitoring through indicators, targets, lessons learned and good practices being transformed into explicit knowledge for a replication of results in different nations.

Findings from the focus group interviews provided in-depth information on the understanding and knowledge management of Sustainability Science. The main findings were that: (i) investment in education and information, (ii) political leadership and governance, (iii) global integrated compromise and partnership, (iv) innovative solutions, and (v) aggregated and reliable indicators are critical points to effectively achieve the SDGs. These results were cross-checked with the main theoretical findings in order to substantiate guidelines for the implementation of the proposed framework, thus seeking to facilitate the implementation and monitoring of SDGs.

\subsection{Guidelines to Tackle Sustainability Challenges}

\section{i. Greater investments in education and information}

Higher education (HE) plays a vital role in attaining SD at a local and global level. Students understand the opportunities that colleges have when it comes to the 
execution of research related to sustainability and to the SDGs (Yuan and Zuo 2013). Moreover, according to Beynaghi et al. (2016), one of the most significant objectives of the SDGs is the pursuit of HE for sustainable development through social collaboration, in order to achieve fundamental and drastic changes in the structure and function of society. It is hugely important then, for socially, environmentally and economically oriented universities and institutions to apply their resources towards the co-creation of a sustainable society. These changes will depend on their mission, focus groups, disciplines, EDS view, main external partners, key-projects, activities and results towards society stakeholders, geographical focus and main involved functions.

According to Bond et al (2010), the integration of knowledge - which concentrates on information, exchange of opinion, and the construction or grouping of data - is the basis for interdisciplinarity and transdisciplinarity because it supports a common understanding of the key-concepts of sustainability. In the future, the ICT applications must be adapted or redesigned so as to promote acceptance between relevant agents, and political incentives may be necessary to introduce additional sustainable concepts, such as the $\mathrm{CO} 2$ footprint for agriculture transport (Mehmann and Teuteberg 2015). A more technologically experienced generation promotes new ways of learning, due to the importance of offering knowledge and skills training at all levels of society. This helps to provide unprecedented opportunities to raise the first connected generation to the level of the first sustainable generation (Chin and Jacobson 2015).

\section{ii. Political leadership and governance}


According to Chasek and Wagner (2016), some lessons learned from the innovative negotiations of the SDGs through the Open Working Group were: avoid block by block negotiations; maintain the open process to all governments and interested observers; encourage strong leadership which can create an atmosphere of understanding and mutual trust; and, construct a single negotiation text. Hák et al. (2016) state that, in order to have an efficient operationalization process - and for the success of the entire SDG agenda - the political process must consider scientific knowledge and evidence at the initial stages of the political cycle.

According to Bergaglio (2016), although many reports and official statements from all over the globe have been acknowledging the need to promote population policies at the core of SD, these calls have not been given their due recognition when it comes to the Planning of SDGs and the international Agenda for development and sustainability.

According to Waage et al. (2015), the synergic opportunities for the implementation of the SDGs are associated with the alignment of objectives and it is up to the local governments to create the necessary governance mechanisms at the national and subnational levels to involve community organizations. The implementation of the objectives would need to challenge the "business as usual" approach. At the same time, new social movements may need to put even more pressure on the existing political and economic powers, thereby levelling the playing field for action through decision. This would encourage those in power to stretch beyond what is a necessary level of accountability to help create the conditions for more participation (Gupta and Vegelin 2016).

The G20 - especially China, chair of the G20 in 2016 - could play an important role in facilitating the implementation of the SDGs, both in internal markets as well as 
internationally, and it has been increasingly active in its contributions to global governance (Li and Zhou 2016). Furthermore, the G20 could make use of its national “development models", such as South Korea and China, which have sailed successfully through the journey of aid beneficiaries to development donors. The G20 could promote the sharing of knowledge and mutual learning for the benefit of its members and for that of lower-income countries. Further, it could establish a peer-review process for the implementation of SDGs in its member countries and take the review results to the summit level.

\section{iii. Global integrated compromise and partnership}

Mugagga and Nabaasa (2016) suggest that through strategic planning and cooperation - along with greater commitment between member states to increase their hydro resources, thereby increasing investment in the sector, elaborating sustainable policy and collaborating with neighboring communities - the management of hydro resources in the African continent could be a key precursor to the achievement of the SDGs.

For Sachs (2012), it is critical for the private sector to be involved from the beginning and the SDGs will require societies worldwide to invest properly in their success. The SDGs must also include incentives for municipal public service companies to report their indicator efforts to national bodies in order to enable aggregations to occur at a national level (Malik et al. 2015).

Moreover, Rickels et al. (2016) state that the development of the general agenda and of the indicator chart has been - and continues to be - organized in such a way to include different opinions and knowledge from different specialists, partners and 
stakeholders. According to Gupta and Vegelin (2016), the monitoring of commitment will need to come from the academic community, as well as from NGOs.

Therefore, it is possible to observe that the SDGs must be integrated into international and national policy, in addition to the necessary and proper coordination, monitoring and evaluation. However, Alleyne et al. (2015) emphasize the importance of countries adopting the SDG goals according to their own circumstances.

\section{iv. Innovative solutions}

According to Koehler (2016), by establishing creative connections between goals and targets, there is room for discrete political evolution. The ideas collected in the SDG agenda, along with soft laws - and especially the ICPD Programme of Action (International Conference on Population and Development) - could serve as an inventory for the formulation of sensitive policy towards gender and climate.

The 193 different governments' commitment, which adopted the 2030 Agenda and the SDGs, needs to be solidified, and it must be done in a creative manner, unifying the policies which can be extracted from the resolution itself, as well as from the set of human rights texts. Further, it must be done subversively (Koehler, 2016).

According to Gellers (2016), crowdsourcing is a new and underestimated method of global civil engagement which provides the means to expand participation in an agenda-defining process and in the development of policy. This can be done in a fashion which is quicker and more inclusive than was possible at any other point of human history.

As an attempt to systematize the ways the SDGs are pursued in higher education, the Hamburg University of Applied Sciences in Germany set-up the World Sustainable Development Research and Transfer Centre (WSD-RTC) 
(https://www.haw-hamburg.de/en/ftz-nk/programmes/wsd-rtc.html). WSD-RTC is a multi-stakeholder, academic based research and transfer centre, which congregates the best available knowledge and technologies on sustainable development, in support of the implementation of the SDGs. The philosophy of WSD-RTC is that the holistic implementation of sustainability measures requires not only political decision-making, but also concrete research, capacity-building and technology transfer, as well as improved collaboration and information and data exchanges among institutions.

It is important that the SDGs explore new paths towards sustainability. The world needs innovative approaches, methods, technologies and new manners of organizing human activity in order to combine life-improvement standards with ecological imperatives (Sachs 2012).

\section{v. Aggregated and reliable indicators}

According to Sachs (2012), the SDGs must include precise, timely and available data to managers, political decision-makers and the public at large. Malik et al. (2015) noted that the SDGs must be "aspirational, universal, communicable and measurable", and must establish the cornerstones for other countries to achieve the global goals between 2015 and 2030. Hák et al. (2016) state that the indicator framework for the SDGs needs more intense conceptual and methodological work, instead of just producing new social, economic and environmental statistics. More global, integrated and scientifically based information is needed when it comes to SD.

Costanza et al. (2016) highlight that it is necessary to develop aggregate indicators which can evaluate the relative contribution of each SDG and their interaction with each other, in order to evaluate general progress and develop a framework of 
political reform and social change. This would aid in achieving the SDGs at a national and global level.

The achievement of the SDGs needs to be evaluated and followed by goals and indicators, and all of them must be carefully analyzed by specialist scientists in order to reinforce a widely overlooked indicator, which has particular relevance (Hák et al 2016).

\section{Lessons Learned: towards the implementation of the SDGs}

According to Brolan et al. (2014), important lessons can be inferred from the old MDGs. The new post-2015 development agenda is more collaborative and participative, and has no tolerance for the repetition of previous bureaucratic matters. Moreover, the SDGs are more in synch with human values and with the principals of universality, transparency, participation, equality, non-discrimination, and liability than the previous objectives (Frey and MacNaughton 2016).

Stevens and Kanie (2016) state that the 2030 Agenda was set out through a long, open and transparent process, involving many agents at several points of the discussion. The decisions were made through collective global action, and introduced new practices to a complex political process which may present new agents, new ideas, and new actions for sustainability.

For Reed et al. (2016), a landscape approach ensures the equal and sustainable use of land, due to it being a potential mechanism for reducing poverty, conserving biodiversity, preserving forests and managing natural resources sustainably, while maintaining food production and mitigating climate change.

Kirigia et al. (2016) call attention to the need for the governing bodies of the World Health Organisation (WHO) to use all available spaces and places properly, and 
to the regional dialogue on health development, in order to mobilize a critical mass of multifold resources to complement the efforts of the Member-States in the execution of SDG 3, from a health perspective.

According to Rickels et al. (2016), a detailed analysis of SDG 14 (Ocean) in the coastal states of the European Union (EU) has demonstrated how the complementary inclusion of compound indicators, which aggregate individual indicators through the application of a generalized medium, may provide important additional information and facilitate the evaluation of sustainable development in general and in the context of the SDGs.

Mboumboue and Njomo (2016) recommend that decision-makers must build clear and trust-inspiring legal conditions in order to create reliability in stable planning, which would stimulate new ventures. They argue that decision-makers must make strong laws and, especially, must guarantee the participation of renewable energy (in all of its forms) in the energetic mix. Authorities must support complementary educational programs which focus on renewable energy and their energetic efficiency.

Shan and Khan (2016) presented, in a case study, the idea of sustainable reverse innovation, which is local innovation present in emerging markets at the global and national level. Through the measurement of the employment of reverse innovation, it is possible to promote sustainability through the use of nine group indicators in three sets of the Triple Bottom Line, related to the sustainable development goals. Therefore, it is possible to foresee the improvement in the living conditions of populations in developing countries as an important contribution from this innovation, thereby ensuring sustainable socio-economical change.

Van Vuuren et al. (2014) suggest that the commitment between hunger eradication, widespread access to energy and the achievement of environmental 
sustainability must be considered if efficient policy is to be implemented. The authors argue that the resolution of the main challenges related to the connection between energy, earth and water requires a wide set of measures to be implemented. They argue that without additional policies, the relative connection to the sustainable development goals will not be reached, despite progress in human development.

As Barnett and Parnell (2016) suggest, the selection of location-specific data and indicators, through which the implementation of the urban agenda will be followed, depends on the ability to share and learn through different contexts, while working in collaboration with different parties - and not just with the government - in different locations.

Plagerson and Ulriksen (2016) identify two significant obstacles for poverty eradication and inequality through social protection: (1) the rising complexity and commitment demanded from social protection answers when going from unidimensional poverty to multidimensional inequality and, (2) the limited convergence of principle arguments to fight inequality. The authors suggest that a robust ethical mandate could help to clarify the objectives of social protection and could reinforce and add precision to the ongoing efforts to accelerate the trajectory towards social protection.

Furthermore, it is necessary to devise intelligent ways of connecting the topdown approach of SDGs to a global bottom-up local action agenda. The SDGs must belong to all of the citizens of the world, and the advancement of ICT provides excellent conditions for young people to be the pioneers of the future in an efficient and economical manner (Chin and Jacobson 2015).

According to Worrall et al. (2009), the planning for the use of land must have referential milestones in order to measure progress towards the SDGs. Management 
objectives must belong to the relevant government agencies, and must be developed through a participative process involving local stakeholders and private companies.

Mehmann and Teuteberg (2015) demonstrate that the applicability of a logistic service provider approach in the fourth part of the bulk agricultural sector supports the execution of the SDGs in transport.

To Schandl et al. (2016), the OECD economies have significant potential to reduce their material production and carbon emissions, with little impact to their economic growth. They argue that the quality of their growth must be the focus of the new SDGs, in order to reach an increase in the local quality of life and a reduction of poverty because, in the future, the investment in green economic strategies will support economic development.

Khalili and Duecker (2013) point out that government initiatives could facilitate the adaptation of strategies as sustainable environmental management. This could be done through the conception and application of political frameworks, as well as the promotion of the availability of financing through the private sector, which has the capacity to promote capital allocation for organizations and companies which are interested in pursuing sustainable operation strategies.

Persson et al. (2016) identify three necessary priorities to facilitate the internalization of national SDG goals: (1) widespread social awareness must be fostered and nourished; civil society and the private sector must be key-agents in the accomplishment of the goals, and must also interpret the SDGs; (2) the outline of a central national goals group is important, as priorities will probably focus upon the implementation process, making it more efficient and manageable; and (3) reports must, for the most part, base themselves on measures that take into account the national and subnational level, not just the progress of the goal's development. 
Li and Zhou (2016) state that G20 could contribute towards the implementation of the SDGs by promoting the sharing of knowledge between countries and the paradigm shift in the architecture of global development, because the group members have different approaches, lessons and development experience which all add to international development.

Finally, the biggest challenge that many organizations may face is to learn how to utilize efficient benchmarking and how to access resources as an essential part of their efforts towards achieving and maintaining sustainable operations.

\section{Conclusions}

As this article has demonstrated, the accomplishment of the 17 Sustainable Development Goals and the 169 targets outlined in "Transforming Our World: The 2030 Agenda for Sustainable Development" is not an easy task. Apart from a review of the literature on the topic, this research presents a novel framework which could help policy-makers, project developers and professionals tackle sustainability challenges. Its implementation will ensure significant contributions towards the achievement of the SDGs.

The agreement launched in September 2015 can only be considered a first step towards the creation of a more inclusive and equal society. The reasons for this are twofold. Firstly, the SDGs commit themselves to ending extreme poverty in all of its forms, including hunger, and invite all citizens to have universal access to essential social services and to basic infrastructure by 2030. For this to become a reality, countries - especially developing ones - must prepare implementation strategies for the national SDGs and make a draft for how they want to achieve this at a national level. Secondly, to achieve the SDGs, more effort is necessary when it comes to changing 
consumption standards and more sustainable production that does not exhaust natural resources for future generations, and promotes prosperity for all. Unless such changes occur, the ongoing population and economic growth will only increase the planetary pressure and escalate social exclusion and inequality.

Although it is difficult to isolate the impact of other development tendencies, it is clear that the SDGs must be used as a reference point for development policy. The challenges raised by the SDGs are integrated and must be pursued together in a holistic way, instead of one by one. When it comes to their implementation, it is important that information on the substantial resources available via -for instance the Sustainable Development Goals fund- are shared more widely, so that more people and organisations may benefit from them, especially those from the developing world.

\subsection{Suggestions for further studies}

Looking to the future, new assessment mechanisms involved in the SDGs still required. There is a need to develop a set of SDGs indicators according to the five guidelines that can be both integrated into this novel framework and assessed and aggregated by means of the four stages described. In addition, the proposed framework, together with the guidelines, needs to be empirically validated and tested at the regional or country level.

Furthermore, it can be said that some unsolved problems or fertile areas with regard to the SDGs implementation issues that require further investigation include the following:

- to disseminate education 4.0 to poorer nations; 
- to encourage co-creative practices to stimulate collaboration and participation in innovative sustainable practices between developed and developing countries;

- to use of Industry 4.0 technologies in sustainable supply chain management, especially in logistics and distribution of resources such as medicines, food and water supply among high-income and low-income countries; and

- to propose a globalized circular economy through a sustainable network between countries, adding more value to the poorest ones.

In addition, we also suggest further applied research through real world case studies, surveys with large samples with diverse groups (such as professors, scientists, researchers, technologists, industry professionals or public workers) or cross-sectional in-depth qualitative interviews with leaders, decision makers and policy makers to better understand how different cultures, geographical areas or could achieve the resourceful targets of the SDGs synergistically.

\section{Appendix A.}

Articles included in the systematic review (bibliographic portfolio).

\begin{tabular}{|c|c|c|c|}
\hline Source & Title & Journal & Citations \\
\hline $\begin{array}{l}\text { Aitsi-Selmi et } \\
\text { al. }(2016)\end{array}$ & $\begin{array}{l}\text { Reflections on a Science and Technology } \\
\text { Agenda for } 21 \text { st Century Disaster Risk } \\
\text { Reduction: }\end{array}$ & $\begin{array}{l}\text { International Journal } \\
\text { of Disaster Risk } \\
\text { Science }\end{array}$ & 47 \\
\hline $\begin{array}{l}\text { Alleyne et al. } \\
(2015)\end{array}$ & Quantifying targets for the SDG health goal. & The Lancet & 8 \\
\hline $\begin{array}{l}\text { Aragon-Correa } \\
\text { et al. (2015) }\end{array}$ & $\begin{array}{l}\text { Sustainability issues and hospitality and } \\
\text { tourism firms' strategies: Analytical review and } \\
\text { future directions }\end{array}$ & $\begin{array}{l}\text { International Journal } \\
\text { of Contemporary } \\
\text { Hospitality } \\
\text { Management }\end{array}$ & 24 \\
\hline Aricò (2014) & $\begin{array}{l}\text { The contribution of the sciences, technology } \\
\text { and innovation to sustainable development: the } \\
\text { application of sustainability science from the } \\
\text { perspective of UNESCO's experience }\end{array}$ & Sustainability Science & 4 \\
\hline
\end{tabular}


Barnett and

Parnell (2016)

Bergaglio

(2016)

Beynaghi et al. (2016)

Bond et al.

(2010)

Brolan et al.

Buse and

Hawkes (2015)

Chasek and

Wagner (2016)

Chin and

Jacobsson

(2015)

Choi et al.

(2016)

Costanza and

Daly (2016)

Dockry et al.

(2015)

Flores Baquero et al. (2015)

Frey and

MacNaughton

(2016)

Gellers (2016)

Giupponi and

Gain (2016)

Griggs et al.

Gupta and

Vegelin (2016)

Hák et al.
Ideas, implementation and indicators:

Epistemologies of the post-2015 urban agenda.

The contemporary illusion: population growth and sustainability.

Future sustainability scenarios for universities: Moving beyond the United Nations Decade of Education for Sustainable Development.

Informal knowledge processes: the underpinning for sustainability outcomes in EIA?

Back to the future: what would the post-2015 global development goals look like if we replicated methods used to construct the Millennium Development Goals?

Health in the sustainable development goals: ready for a paradigm shift?

Breaking the mold: a new type of multilateral sustainable development negotiation.

TheGoals.org: Mobile global education on the Sustainable Development Goals.

Supporting the measurement of the United Nations' sustainable development goal 11 through the use of national urban information systems and open geospatial technologies: a case study of south Korea.

Modelling and Measuring sustainable wellbeing in connection with the UN Sustainable Development Goals.

Sustainable development education, practice, and research: an indigenous model of sustainable development at the College of Menominee Nation, Keshena, WI, USA.

Measuring disparities in access to water based on the normative content of the human right.

A Human Rights Lens on Full Employment and Decent Work in the 2030 Sustainable Development Agenda.

Crowdsourcing global governance: sustainable development goals, civil society, and the pursuit of democratic legitimacy.

Integrated spatial assessment of the water, energy and food dimensions of the Sustainable Development Goals.

Policy: Sustainable development goals for people and planet.

Sustainable development goals and inclusive development.

Sustainable Development Goals: A need for relevant indicators.
Environment and

Urbanization

Environment,

Development and

Sustainability

Journal of Cleaner

Production

Journal of Cleaner

Production

Globalization and

Health

Globalization and

Health

International

Environmental

Agreements: Politics,

Law and Economics

Journal of Cleaner

Production

Open Geospatial Data,

Software and

Standards

Ecological Economics

Sustainability Science

Social Indicators

Research

Journal of Workplace

Rights

International

Environmental

Agreements: Politics, Law and Economics

Regional

Environmental

Change

Nature

International

Environmental

Agreements: Politics,

Law and Economics

Ecological Indicators

3 52 7 . 95

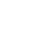
0

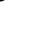


Holm et al. (2016)

Hutton and

Chase (2016)

Jasovský et al.

Jayasooria

(2016)

Khalili and

Duecker (2013)

Kirigia et al. (2016)

Koehler (2016)

Kumi et al. (2014)

Leal Filho et al.

Li and Zhou

Maas et al.

Malik et al.

Maxwell et al. (2015)

Mboumboue and Njomo (2016)

Mehmann and Teuteberg (2015)

Mugagga and Nabaasa (2016)

Munamati et al. Exploring the determinants of sanitation

Persson et al. (2016) health risks in Malawi.

The Knowledge Base for Achieving the Water Supply, Sanitation and Hygiene.

Antimicrobial resistance - a threat to the world's sustainable development. Work Practice in Malaysia. in design of sustainable environmental management system framework. dialogues in the African Region. policy? nexus in developing countries. development.

Achieving the Sustainable Development Perspective.

Advancing the integration of corporate reporting. (SDGs). targets. households in developing countries:

Cameroon's case study. German agricultural bulk logistics sector.

The centrality of water resources to the on the African continent success in Sub-Saharan Africa.

Follow-up and Review of the Sustainable Development Goals: Alignment vs.
Achieving the sustainable development goals: a Journal of Health, case study of the complexity of water quality Sustainable Development Goal Targets on

Sustainable Development Goals and Social Work: Opportunities and Challenges for Social

Application of multi-criteria decision analysis

Space and place for WHO health development

Tapping the Sustainable Development Goals

for progressive gender equity and equality

Can post-2015 sustainable development goals survive neoliberalism? A critical examination of the sustainable development-neoliberalism

The future we want: Key issues on sustainable development in higher education after Rio and the UN decade of education for sustainable Goals : The Role for the G20 from China's sustainability measurement, management and

A global indicator of wastewater treatment to inform the Sustainable Development Goals

Being smart about SMART environmental

Potential contribution of renewables to the improvement of living conditions of poor rura

The fourth-party logistics service provider approach to support sustainable development goals in transportation - a case study of the realization of Sustainable Development Goals (SDG). A review of potentials and constraints Internalization.
Population and

Nutrition

International Journal

of Environmental

Research and Public

Health

Upsala Journal of

Medical Sciences

Journal of Human

Rights and Social

Work

Journal of Cleaner

Production

BMC Health Services

Research

Gender \&

Development

Environment

Development and

Sustainability

International Journal of Sustainability in

Higher Education

China \& World

Economy

Journal of Cleaner

Production

Environmental

Science \& Policy

Science

Renewable \&

Sustainable Energy

Reviews

Journal of Cleaner

Production

International Soil and Water Conservation

Research

Water Research

Review of European

Community and

International

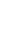


Plagerson and Can social protection address both poverty and

Ulriksen (2016) inequality in principle and practice?

Reed et al.

(2016)

Rickels et al.

(2016)

Sachs (2012)

Schandl et al.

Shan and Khan

(2016)

Stafford-Smith

et al. (2016)

Stevens and

Kanie (2016)

Terama et al.

Urmee and Md

(2016)

Van Vuuren et

al. (2014)

Waage et al.

(2015)

Worral et al. (2009)

Wuelser and

Pohl (2016)

Yuan and Zuo

(2013)

Integrated landscape approaches to managing social and environmental issues in the tropics: learning from the past to guide the future.

Indicators for monitoring sustainable

development goals: An application to oceanic development in the European Union.

From millennium development goals to sustainable development goals.

Decoupling global environmental pressure and economic growth: scenarios for energy use, materials use and carbon emissions.

Implications of Reverse Innovation for SocioEconomic Sustainability: A Case Study of Philips China.

Integration: the key to implementing the

Sustainable Development Goals.

The transformative potential of the Sustainable.

Accounting for the environment as an

economic asset: global progress and realizing the 2030 Agenda for Sustainable Development.

Social, cultural and political dimensions of offgrid renewable energy programs in developing countries.

Pathways to achieve a set of ambitious global sustainability objectives by 2050: Explorations using the IMAGE integrated assessment model.

Governing the UN sustainable development

goals: Interactions, infrastructures, and institutions.

Towards a sustainability criteria and indicators framework for legacy mine land.

How researchers frame scientific contributions to sustainable development: a typology based on grounded theory.

A critical assessment of the Higher Education for Sustainable Development from students' perspectives - A Chinese study.
Global Social Policy

Global Change

Biology

Earth's Future

Lancet

Journal of Cleaner

Production

Sustainability

4

Sustainability Science

International

Environmental

Agreements: Politics,

Law and Economics

Sustainability Science

Renewable Energy

Technological

Forecasting and Social

The Lancet Global

Health

Journal of Cleaner

Production

Sustainability Science

Journal of Cleaner

Production

\section{References}

Aitsi-Selmi, A., Murray, V., Wannous, C., Dickinson, C., Johnston, D., Kawasaki, A., Stevance, A.-S., Yeung, T., 2016. Reflections on a Science and Technology Agenda for 21st Century Disaster Risk Reduction. Int. J. Disaster Risk Sci. 7, 129. doi:10.1007/s13753-016-0081-x

Alleyne, G., Beaglehole, R., Bonita, R., 2015. Quantifying targets for the SDG health goal. Lancet 385, 208-209. doi:10.1016/S0140-6736(14)61655-X 
Aragon-Correa, J.A., Martin-Tapia, I., de la Torre-Ruiz, J.M., 2015. Sustainability issues and hospitality and tourism firms' strategies. Int. J. Contemp. Hosp. Manag. 27, 498-522. doi:10.1108/IJCHM-11-2014-0564

Aricò, S., 2014. The contribution of the sciences, technology and innovation to sustainable development: the application of sustainability science from the perspective of UNESCO's experience. Sustain. Sci. 9, 453-462. doi:10.1007/s11625-014-0256-6

Barnett, C., Parnell, S., 2016. Ideas, implementation and indicators: Epistemologies of the post-2015 urban agenda. Environ. Urban. 28, 87-98. doi:10.1177/0956247815621473

Bergaglio, M., 2016. The contemporary illusion: population growth and sustainability. Environ. Dev. Sustain. doi:10.1007/s10668-016-9842-3

Beynaghi, A., Trencher, G., Moztarzadeh, F., Mozafari, M., Maknoon, R., Leal Filho, W., 2016. Future sustainability scenarios for universities: Moving beyond the United Nations Decade of Education for Sustainable Development. J. Clean. Prod. 112, 3464-3478. doi:10.1016/j.jclepro.2015.10.117

Bond, A.J., Viegas, C. V., Coelho de Souza Reinisch Coelho, C., Selig, P.M., 2010. Informal knowledge processes: the underpinning for sustainability outcomes in EIA? J. Clean. Prod. 18, 6-13. doi:10.1016/j.jclepro.2009.09.002

Brolan, C.E., Lee, S., Kim, D., Hill, P.S., 2014. Back to the future: what would the post2015 global development goals look like if we replicated methods used to construct the Millennium Development Goals? Global. Health 10, 19. doi:10.1186/1744-8603-10-19

Buse, K., Hawkes, S., 2015. Health in the sustainable development goals: ready for a paradigm shift? Global. Health 11, 13. doi:10.1186/s12992-015-0098-8

Chasek, P.S., Wagner, L.M., 2016. Breaking the mold: a new type of multilateral sustainable development negotiation. Int. Environ. Agreements Polit. Law Econ. 16, 397-413. doi:10.1007/s10784-016-9320-2

Chin, A., Jacobsson, T., 2015. TheGoals.org: Mobile global education on the Sustainable Development Goals. J. Clean. Prod. 123, 227-229. doi:10.1016/j.jclepro.2015.08.061

Choi, J., Hwang, M., Kim, G., Seong, J., Ahn, J., 2016. Supporting the measurement of the United Nations' sustainable development goal 11 through the use of national urban information systems and open geospatial technologies: a case study of south Korea. Open Geospatial Data, Softw. Stand. 1, 4. doi:10.1186/s40965-016-0005-0

Costanza, R., Daly, L., Fioramonti, L., Giovannini, E., Kubiszewski, I., Fogh, L., 2016. Modelling and Measuring sustainable wellbeing in connection with the UN Sustainable Development Goals. Ecol. Econ. 1-8. doi:10.1016/j.ecolecon.2016.07.009

Deloitte and CSR Netherlands, 2015. Integrated Reporting as a Driver for Integrated Thinking? Maturity of $<\mathrm{IR}>$ in the Netherlands. Utrecht, The Netherlands. 
Dockry, M.J., Hall, K., van Lopik, W., Caldwell, C.M., 2015. Sustainable development education, practice, and research: an indigenous model of sustainable development at the College of Menominee Nation, Keshena, WI, USA. Sustain. Sci. 127-138. doi:10.1007/s11625-015-0304-X

Flores Baquero, O., Jiménez Fdez. de Palencia, A., Pérez Foguet, A., 2015. Measuring disparities in access to water based on the normative content of the human right. Soc. Indic. Res. 2, 741-759. doi:10.1007/s11205-015-0976-8

Frey, D.F., MacNaughton, G., 2016. A Human Rights Lens on Full Employment and Decent Work in the 2030 Sustainable Development Agenda. J. Work. Rights 6, 755-829. doi:10.1177/2158244016649580

Gellers, J.C., 2016. Crowdsourcing global governance: sustainable development goals, civil society, and the pursuit of democratic legitimacy. Int. Environ. Agreements Polit. Law Econ. 16, 415-432. doi:10.1007/s10784-016-9322-0

Giupponi, C., Gain, A.K., 2016. Integrated spatial assessment of the water, energy and food dimensions of the Sustainable Development Goals. Reg. Environ. Chang. doi:10.1007/s10113-016-0998-z

Griggs, D., Stafford-Smith, M., Gaffney, O., Rockström, J., Ohman, M.C., Shyamsundar, P., Steffen, W., Glaser, G., Kanie, N., Noble, I., 2013. Policy: Sustainable development goals for people and planet. Nature 495, 305-7. doi: $10.1038 / 495305 \mathrm{a}$

Gupta, J., Vegelin, C., 2016. Sustainable development goals and inclusive development. Int. Environ. Agreements Polit. Law Econ. 16, 1-16. doi:10.1007/s10784-0169323-z

Hák, T., Janousková, S., Moldan, B., 2016. Sustainable Development Goals: A need for relevant indicators. Ecol. Indic. 60, 565-573. doi:10.1016/j.ecolind.2015.08.003

Holm, R., Wandschneider, P., Felsot, A., Msilimba, G., 2016. Achieving the sustainable development goals: a case study of the complexity of water quality health risks in Malawi. J. Heal. Popul. Nutr. 35, 20. doi:10.1186/s41043-016-0057-x

Hutton, G., Chase, C., 2016. The Knowledge Base for Achieving the Sustainable Development Goal Targets on Water Supply, Sanitation and Hygiene. Int. J. Environ. Res. Public Health 13, 536. doi:10.3390/ijerph13060536

Jasovský, D., Littmann, J., Zorzet, A., Cars, O., 2016. Antimicrobial resistance-a threat to the world's sustainable development. Ups. J. Med. Sci. 121, 159-164. doi:10.1080/03009734.2016.1195900

Jayasooria, D., 2016. Sustainable Development Goals and Social Work: Opportunities and Challenges for Social Work Practice in Malaysia. J. Hum. Rights Soc. Work 1, 19-29. doi:10.1007/s41134-016-0007-y

Khalili, N.R., Duecker, S., 2013. Application of multi-criteria decision analysis in design of sustainable environmental management system framework. J. Clean. Prod. 47, 188-198. doi:10.1016/j.jclepro.2012.10.044

Kirigia, J.M., Nabyonga-Orem, J., Dovlo, D.Y.T., 2016. Space and place for WHO 
health development dialogues in the African Region. BMC Health Serv. Res. 16, 221. doi:10.1186/s12913-016-1452-0

Koehler, G., 2016. Tapping the Sustainable Development Goals for progressive gender equity and equality policy? Gend. Dev. 24, 53-68. doi:10.1080/13552074.2016.1142217

Kumi, E., Arhin, A.A., Yeboah, T., 2014. Can post-2015 sustainable development goals survive neoliberalism? A critical examination of the sustainable developmentneoliberalism nexus in developing countries. Env. Dev Sustain 16, 539-554. doi:10.1007/s10668-013-9492-7

Leal Filho, W., Manolas, E., Pace, P., 2015. The future we want: Key issues on sustainable development in higher education after Rio and the UN decade of education for sustainable development. Int. J. Sustain. High. Educ. 16 (1), 112129. doi: 10.1108/IJSHE-03-2014-0036

Li, X., Zhou, T., 2016. Achieving the Sustainable Development Goals : The Role for the G20 from China's s Perspective. China World Econ. 24, 55-72.

Maas, K., Schaltegger, S., Crutzen, N., 2016. Advancing the integration of corporate sustainability measurement, management and reporting. J. Clean. Prod. 133, 859862. doi:10.1016/j.jclepro.2016.06.006

Malik, O.A., Hsu, A., Johnson, L.A., de Sherbinin, A., 2015. A global indicator of wastewater treatment to inform the Sustainable Development Goals (SDGs). Environ. Sci. Policy 48, 172-185. doi:10.1016/j.envsci.2015.01.005

Maxwell, S.L., Milner-Gulland, E.J., Jones, J.P.G., Knight, A.T., Bunnefeld, N., Nuno, A., Rhodes, J.R., 2015. Being smart about SMART environmental targets. Science 347 (6226), 1075-1076

Mboumboue, E., Njomo, D., 2016. Potential contribution of renewables to the improvement of living conditions of poor rural households in developing countries: Cameroon's case study. Renew. Sustain. Energy Rev. 61, 266-279. doi:10.1016/j.rser.2016.04.003

Mehmann, J., Teuteberg, F., 2015. The fourth-party logistics service provider approach to support sustainable development goals in transportation - a case study of the German agricultural bulk logistics sector. J. Clean. Prod. 126, 382-393. doi:10.1016/j.jclepro.2016.03.095

Mugagga, F., Nabaasa, B.B., 2016. The centrality of water resources to the realization of Sustainable Development Goals (SDG). A review of potentials and constraints on the African continent. Int. Soil Water Conserv. Res. 1-9. doi:10.1016/j.iswcr.2016.05.004

Munamati, M., Nhapi, I., Misi, S., 2016. Exploring the determinants of sanitation success in Sub-Saharan Africa. Water Res. 103, 435-443. doi:10.1016/j.watres.2016.07.030

Persson, Å., Weitz, N., Nilsson, M., 2016. Follow-up and Review of the Sustainable Development Goals: Alignment vs. Internalization. Rev. Eur. Comp. Int. Environ. Law 25, 59-68. doi:10.1111/reel.12150 
Plagerson, S., Ulriksen, M.S., 2016. Can social protection address both poverty and inequality in principle and practice? Glob. Soc. Policy 1468018115622521-. doi:10.1177/1468018115622521

Reed, J., Van Vianen, J., Deakin, E.L., Barlow, J., Sunderland, T., 2016. Integrated landscape approaches to managing social and environmental issues in the tropics: learning from the past to guide the future. Glob. Chang. Biol. n/a-n/a. doi:10.1111/gcb.13284

Ribeiro J., 2003. Grupos focados: teoria e aplicações. FEENG, Porto Alegre

Rickels, W., Dovern, J., Hoffmann, J., Quaas, M.F., Schmidt, J.O., Visbeck, M., 2016. Indicators for monitoring sustainable development goals: An application to oceanic development in the European Union. Earth's Futur. doi:10.1002/2016EF000353.Abstract

Sachs, J.D., 2012. From millennium development goals to sustainable development goals. Lancet 379, 2206-2211. doi:10.1016/S0140-6736(12)60685-0

Schandl, H., Hatfield-Dodds, S., Wiedmann, T., Geschke, A., Cai, Y., West, J., Newth, D., Baynes, T., Lenzen, M., Owen, A., 2016. Decoupling global environmental pressure and economic growth: scenarios for energy use, materials use and carbon emissions. J. Clean. Prod. 132, 45-56. doi:10.1016/j.jclepro.2015.06.100

Shan, J., Khan, M., 2016. Implications of Reverse Innovation for Socio-Economic Sustainability: A Case Study of Philips China. Sustainability 8, 530. doi:10.3390/su8060530

Stafford-Smith, M., Griggs, D., Gaffney, O., Ullah, F., Reyers, B., Kanie, N., Stigson, B., Shrivastava, P., Leach, M., O'Connell, D., 2016. Integration: the key to implementing the Sustainable Development Goals. Sustain. Sci. 1-9. doi:10.1007/s11625-016-0383-3

Stevens, C., Kanie, N., 2016. The transformative potential of the Sustainable. Int. Environ. Agreements Polit. Law Econ. 16, 393-396. doi:10.1007/s10784-0169324-y

Terama, E., Milligan, B., Jiménez-Aybar, R., Mace, G.M., Ekins, P., 2015. Accounting for the environment as an economic asset: global progress and realizing the 2030 Agenda for Sustainable Development. Sustain. Sci. 1-6. doi:10.1007/s11625-0150350-4

Tortorella $\mathrm{G}$ et al., 2008. Identificação de fatores que afetam a sustentabilidade de melhorias em células de manufatura usando grupos focados. In: XXVIII Encontro Nacional de Engenharia de Produção, Rio de Janeiro

UN General Assembly, 2012. The future we want. A/RES.66/288 (11 September). http://www.un.org/ga/ search/view_doc.asp?symbol=A/RES/66/288\&Lang=E. Accessed May 2, 2015

United Nations Development Program (UNDP), 2006. Millennium development goals. http://www.undp.org/ mdg/basics.shtml. Accessed 26 August 2016

Urmee, T., Md, A., 2016. Social, cultural and political dimensions of off-grid renewable 
energy programs in developing countries. Renew. Energy 93, 159-167. doi:10.1016/j.renene.2016.02.040

Van Vuuren, D.P., Kok, M., Lucas, P.L., Prins, A.G., Alkemade, R., van den Berg, M., Bouwman, L., van der Esch, S., Jeuken, M., Kram, T., Stehfest, E., 2014. Pathways to achieve a set of ambitious global sustainability objectives by 2050: Explorations using the IMAGE integrated assessment model. Technol. Forecast. Soc. Change 98, 303-323. doi:10.1016/j.techfore.2015.03.005

Waage, J., Yap, C., Bell, S., Levy, C., Mace, G., Pegram, T., Unterhalter, E., Dasandi, N., Hudson, D., Kock, R., Mayhew, S., Marx, C., Poole, N., 2015. Governing the UN sustainable development goals: Interactions, infrastructures, and institutions. Lancet Glob. Heal. 3, e251-e252. doi:10.1016/S2214-109X(15)70112-9

Worrall, R., Neil, D., Brereton, D., Mulligan, D., 2009. Towards a sustainability criteria and indicators framework for legacy mine land. J. Clean. Prod. 17, 1426-1434. doi:10.1016/j.jclepro.2009.04.013

Wuelser, G., Pohl, C., 2016. How researchers frame scientific contributions to sustainable development: a typology based on grounded theory. Sustain. Sci. 11, 1-12. doi:10.1007/s11625-016-0363-7

Yuan, X., Zuo, J., 2013. A critical assessment of the Higher Education for Sustainable Development from students' perspectives - A Chinese study. J. Clean. Prod. 48, 108-115. doi:10.1016/j.jclepro.2012.10.041 